\title{
BMJ Open A retrospective cohort study of mode of delivery among public and private patients in an integrated maternity hospital setting
}

Deirdre J Murphy, ${ }^{1}$ Tom Fahey ${ }^{2}$

To cite: Murphy DJ, Fahey T. A retrospective cohort study of mode of delivery among public and private patients in an integrated maternity hospital setting. BMJ Open 2013;3: 0003865 .

doi:10.1136/bmjopen-2013003865

\section{- Prepublication for this} paper is available online. To view these files please visit the journal online (http://dx.doi.org/10.1136/ bmjopen-2013-003865).

Received 21 August 2013 Revised 6 October 2013 Accepted 7 October 2013

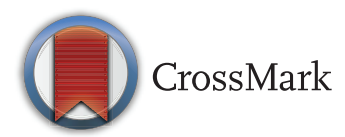

${ }^{1}$ Department of Obstetrics and Gynaecology, Trinity College, University of Dublin, Dublin, Republic of Ireland ${ }^{2}$ Division of Population Health Sciences, Royal College of Surgeons in Ireland, Dublin, Republic of Ireland

Correspondence to Professor Deirdre J Murphy; deirdre.j.murphy@tcd.ie

\section{ABSTRACT}

Objective: To examine the associations between mode of delivery and public versus privately funded obstetric care within the same hospital setting.

Design: Retrospective cohort study.

Setting: Urban maternity hospital in Ireland.

Population: A total of 30053 women with singleton pregnancies who delivered between 2008 and 2011.

Methods: The study population was divided into those who booked for obstetric care within the public $(n=24574)$ or private clinics $(n=5479)$. Logistic regression analyses were performed to examine the associations between operative delivery and type of care, adjusting for potential confounding factors.

Main outcome measures: Caesarean section (scheduled or emergency), operative vaginal delivery (vacuum or forceps), indication for caesarean section as classified by the operator.

Results: Compared with public patients, private patients were more likely to be delivered by caesarean section (34.4\% vs $22.5 \%$, OR $1.81 ; 95 \% \mathrm{Cl} 1.70$ to 1.93 ) or operative vaginal delivery ( $20.1 \%$ vs $16.5 \%$, OR $1.28 ; 95 \%$ Cl 1.19 to 1.38). The greatest disparity was for scheduled caesarean sections; differences persisted for nulliparous and parous women after controlling for medical and social differences between the groups (nulliparous $11.9 \%$ vs $4.6 \%$, adjusted (adj) OR 1.82; 95\% Cl 1.49 to 2.24 and parous $26 \%$ vs $12.2 \%$, adj OR $2.08 ; 95 \% \mathrm{Cl} 1.86$ to 2.32 ). Scheduled repeat caesarean section accounted for most of the disparity among parous patients. Maternal request per se was an uncommonly reported indication for caesarean section (35 in each group, $p<0.000$ ).

Conclusions: Privately funded obstetric care is associated with higher rates of operative deliveries that are not fully accounted for by medical or obstetric risk differences.

\section{INTRODUCTION}

Public and private healthcare have coexisted within Irish hospitals for decades with critics claiming that this results in a two-tier system. ${ }^{1}$ Following the last general election, the coalition government in its 'Programme for Government' committed to introducing a single model of healthcare based on universal health insurance. ${ }^{2}$ The precise details of

\section{Strengths and limitations of this study}

- This large cohort study is unique in that it compares the delivery outcomes of public and private patients cared for by the same group of obstetricians within the same hospital setting. The dataset had detailed information on sociodemographic, medical and obstetric factors that contribute to decisions on mode of delivery. Perinatal outcomes were available up until the first hospital discharge.

- It was not possible to determine whether the decision for an operative delivery was driven by the obstetrician or the woman or both.

this new health system are yet to be determined. In the meantime, publicly funded hospitals are permitted to treat public and private patients at a ratio of $80: 20 .{ }^{3}$ In contrast, the National Health Service in the UK, which has taken great pride in providing free healthcare for all, is in the process of introducing a system not unlike the current Irish system, allowing up to $49 \%$ of hospital income to be generated from 'self-funded' patients. ${ }^{4}$ Undoubtedly the admission of private patients brings a much needed resource into an overstretched system. Up to $20 \%$ of the hospital budget in Dublin Maternity Hospitals is generated from private accommodation charges (Annual Report http://www.coombe.ie). What is unclear is whether private care within a publicly funded setting incurs higher rates of interventions, and whether these costly interventions (investigations, operations, postoperative care) are justified by the risk profile of the patients. Data from the USA reveal the downside of a private funded healthcare system, with overtreatment due to payment for units of service, and financial incentives that reward inefficiency such as payment for complications and re-admissions. ${ }^{5}$

The past few decades have seen a dramatic rise in the rates of caesarean section, from 
$5 \%$ in the 1970 s to over $50 \%$ in some countries in the late 1990s. ${ }^{6-8}$ The reasons for this are multifactorial and have been attributed to increasing maternal age, medical comorbidities, obesity, induction of labour, elective repeat caesarean section, and caesarean section on maternal request. ${ }^{9-13}$ Caesarean section rates of $20-30 \%$ are now the norm throughout the UK and Ireland (http://www. birthchoiceuk.com and http://www.cuidiu-ict.ie). ${ }^{14}{ }^{15}$ There is ongoing debate whether rates of caesarean section could or should be lowered, and whether the associated complications are justified. ${ }^{16-19}$ Most health professionals agree that the management of a woman's first birth is likely to have the biggest impact on overall rates of caesarean section. ${ }^{13}$ Among parous women, different thresholds for attempting a vaginal birth after a previous caesarean section (VBAC) contribute to much of the variation between maternity units. ${ }^{\text {? }}$

While the association between private obstetric care and higher rates of caesarean section has been recognised for some time, there has been limited research addressing whether this association is reflected in differences in the risk profiles of public and private patients and whether it impacts on perinatal outcomes. ${ }^{20-22}$ The aim of this study was to examine the mode of delivery among a cohort of women booked for public or privately funded obstetric care within the same clinical setting, addressing the complex influence of social, medical and obstetric factors on mode of delivery.

\section{METHODS}

Study design

A retrospective cohort study was conducted using the electronic booking and delivery records of women with singleton pregnancies who delivered in a large urban maternity hospital in Ireland between January 2008 and July 2011. The unit delivers between 8000 and 9000 women each year and obstetric care is provided by approximately 14 consultants and 16 obstetric trainees. Data from the first antenatal booking interviews were linked to the electronic delivery record and neonatal records with information on the neonate up until the first hospital discharge. Comprehensive records are available routinely for all deliveries of $\geq 24$ weeks' gestation or $500 \mathrm{~g}$ weight. The completeness and accuracy of the database has been validated for previous studies. ${ }^{13}$ The study was limited to women with singleton pregnancies. Women with multiple pregnancies receive care in a multiple birth clinic under the direction of a single consultant and would not represent the breadth of obstetric practice.

\section{Comparison groups}

Study participants were subdivided into two groups based on whether they booked for private or public obstetric care. Private patients choose their own consultant and either self-refer or are referred by their general practitioner or a specialist (eg, from a fertility clinic).
The named consultant provides continuity of care throughout the antenatal, intrapartum and postnatal period with occasional cross-cover by a nominated consultant colleague. Public patients are booked under a consultant team and care is shared between midwives, the general practitioner and the obstetric team including doctors in training. A further category called 'semiprivate care' is similar to public patient care except for the type of accommodation available to the patient in the postnatal period. For the purposes of this study, semiprivate patients were classified as public patients. All patients in labour or requiring an operative delivery, whether public or private, are cared for by the same team of midwives and theatre staff on the delivery suite and operating theatre floor, respectively. Hospital protocols and guidelines are applied across the patient population unless stipulated otherwise by the consultant responsible for a particular patient.

\section{Maternal characteristics}

In addition to the type of obstetric care, information on the following maternal characteristics was extracted from the electronic records: maternal age, marital status, socioeconomic group, nationality, planning of pregnancy, gestational age at booking, smoking, alcohol use, history of illicit drug use and referral to a social worker. Gestational age was estimated from the calculation based on the first day of the last menstrual period; however, the routine booking ultrasound scan estimate was preferred if the dates were uncertain or there was a discrepancy of more than 7 days. Socioeconomic groups were classified as professional/manager, home duties, nonmanual, manual, unemployed and non-classifiable. Nationality was recorded as Irish or non-Irish and was further subdivided into country of origin. Gestational age at booking was banded into three groups: $<12,12$ 20 and $>20$ weeks. Smokers were defined as women who were current smokers at the time of attendance at their first antenatal visit. Current alcohol use was classified according to the woman's reported use of alcohol at the time of the first visit.

\section{Medical factors}

Data were recorded for medical, psychiatric, past obstetric, antenatal and fetal complications. Medical disorders included hypertension requiring treatment, diabetes mellitus (types 1 and 2), gestational diabetes requiring insulin treatment, respiratory disease including severe asthma, cardiac disease other than history of a murmur, haematological conditions including previous venous thromboembolism, inflammatory bowel disease, renal disease other than a single urinary tract infection, autoimmune disease, neurological disease including epilepsy and serious skin disorders. A detailed psychiatric history was elicited for current or previous depression requiring treatment, previous postnatal depression requiring treatment and any history of major psychiatric illness or psychosis. The booking blood results were available and 
included Hepatitis C and HIV status. Body mass index (BMI) was recorded and a BMI $\geq 30.0$ was classified as overweight and warranted screening for gestational diabetes with a glucose tolerance test at 26-28 weeks' gestation.

\section{Obstetric factors}

A detailed obstetric history was recorded including previous miscarriage, termination or perinatal death. Recurrent miscarriage was classified as any three previous miscarriages as the timing and/or a change of partner was not always clear. Assisted conception in the current pregnancy included ovulation induction, intrauterine insemination or any type of in vitro fertilisation. The medical records were updated at the time of delivery to include antenatal maternal and fetal complications in the current pregnancy. Fetal complications included structural abnormalities, suspected intrauterine growth restriction, oligohydramnios, abnormal umbilical artery Doppler studies or preterm prelabour rupture of membranes. Maternal complications included admission for preeclampsia, significant antepartum haemorrhage, unstable lie or any infection requiring intravenous antibiotics.

\section{Mode of delivery}

The mode of delivery was classified as spontaneous vaginal delivery, operative vaginal delivery or caesarean section. Operative vaginal deliveries were subclassified as either vacuum or forceps. Where more than one instrument was used, the mode of delivery was designated based on the instrument used to complete the delivery. Caesarean sections were classified as scheduled or emergency. A scheduled caesarean section was planned electively and booked on the designated consultant's operating list. Emergency caesarean sections occurred in labour or with no labour. Emergency caesarean sections in labour were subclassified according to whether labour was of spontaneous onset or induced. The classification emergency caesarean section with no labour was used where the delivery was arranged at short notice, usually due to a maternal or fetal complication, and had to be accommodated on the first available list or as part of the out-of-hours service. The indication for caesarean section was coded according to the operator's recorded primary indication. For example, where breech presentation and previous caesarean section were recorded, the primary indication was coded as malpresentation. For emergency caesarean sections, failure to progress and fetal heart rate abnormalities frequently coexisted and were coded as labour complication. Maternal request was coded as such where this was the only indication reported by the operator.

\section{Perinatal outcomes}

Perinatal outcome measures included gestational age at delivery, birth weight, infant gender, infant's Apgar scores at 1 and $5 \mathrm{~min}$, any congenital abnormalities, evidence of aneuploidy (trisomy 21, 18, 13, Turner's syndrome $\mathrm{XO}$ ) and admission to the neonatal unit. Preterm birth was defined as the birth of a live baby at $<37$ completed weeks' gestation. Very preterm birth was defined as the birth of a live baby at $<32$ weeks' gestation. Small for gestational age (SGA) was defined as a birth weight less than the 10th centile using individualised birth weight ratios (corrected for maternal height and weight, parity, infant sex, ethnicity and gestation) http://www.gestation.net. Stillbirth was defined as delivery of a baby showing no signs of life at or after 24 weeks' gestation or weighing $\geq 500 \mathrm{~g}$. Perinatal death included stillbirths and early neonatal deaths (defined as the death of a baby within the first 7 days of life). Congenital anomalies were identified from records of a physical examination of all babies after delivery and from neonatal discharge records.

\section{Statistical analysis}

The analyses were performed using the Statistical Package for Social Sciences (SPSS V.15). The plan of analysis is presented in four stages: first, descriptive statistics were generated for sociodemographic, medical and obstetric characteristics of public and private patients. Univariable logistic regression analyses were performed to measure the association between type of care (private vs public) and these characteristics. Second, further univariable comparisons were performed to measure the association between type of care and mode of delivery. Multivariable stepwise logistic regression analyses were adjusted for baseline differences between the groups. Potential confounding factors included maternal age and BMI (both continuous variables), marital status, socioeconomic status, nationality (all categories), parity, smoking, medical disorders, psychiatric disorders, assisted conception, previous perinatal death, antenatal or fetal complications in the current pregnancy (all binary). These factors were chosen because of their known or potential association with mode of delivery and adverse perinatal outcome. Type of care (private vs public) and mode of delivery were also examined in relation to parity (nulliparous or parous). Finally, perinatal outcomes are reported in relation to type of care (private vs public). Results are reported as proportions, OR and $95 \%$ CI. The reported indications for caesarean section were compared using $\chi^{2}$ tests for difference in proportions or Fisher exact tests where the numbers were small.

Analysis of the dataset was approved by the hospital research ethics committee. Individual patient consent was not deemed necessary as the data are collected routinely and anonymised for analysis (Study No: 22-2009 and updated approval 09-2011).

\section{RESULTS}

\section{Descriptive characteristics}

A total of 30053 antenatal booking and delivery records were available for analysis and of these, 24574 were 
women (82\%) booked in the public clinics and 5479 (18\%) booked for private care. A small number of women each year were booked for antenatal care but delivered elsewhere and were not included in the cohort. There were very few missing responses for individual data items. Compared with public patients, private patients were more likely to be older, of higher socioeconomic group and to be Irish (table 1). Private patients were less likely to be single, nulliparous, to have an unplanned pregnancy, to book late ( $>20$ weeks' gestation), or to smoke, drink alcohol in pregnancy or have used illicit drugs. Private patients were less likely to have a medical disorder, psychiatric history, positive test for hepatitis C or HIV or an increased BMI but were more likely to have a history of assisted conception, recurrent miscarriage or previous perinatal death (table 2). The incidence of fetal and maternal complications was similar between the two groups.

\section{Mode of delivery-overall and stratified by parity}

Operative delivery rates were higher among private than public patients (table 3). Operative vaginal delivery rates were higher for vacuum and forceps deliveries (adjusted (adj) OR 1.47; 95\% CI 1.32 to 1.65 and adj OR 1.21; $95 \%$ CI 1.06 to 1.37 , respectively). The greatest disparity between private and public patients was for scheduled caesarean sections (private $21 \%$ vs public $8.9 \%$, crude OR 2.71; $95 \%$ CI 2.51 to 2.93 ). The association was attenuated after controlling for differences in maternal sociodemographic, medical and obstetric factors (adj OR 1.99; 95\% CI 1.80 to 2.18). Almost all of the attenuation was attributable to adjustment for maternal age and socioeconomic group. Rates of emergency caesarean section were similar $(13.5 \%$ vs $13.6 \%$, adj OR 0.97 ; $95 \%$ CI 0.88 to 1.08 ).

The differences in operative delivery rates persisted within the subgroups of nulliparous and parous patients (table 4). Among nulliparous women, private patients had higher rates of scheduled caesarean section $(11.9 \%$ vs $4.6 \%$, adj OR 1.82; $95 \%$ CI 1.49 to 2.24 ) and emergency caesarean section with no labour $(6 \%$ vs $3.3 \%$, adj OR $1.63 ; 95 \%$ CI 1.25 to 2.13 ) but similar rates of emergency caesarean section in labour. Among parous women, private patients had higher rates of scheduled caesarean section (26\% vs $12.2 \%$, adj OR 2.08 ; $95 \%$ CI 1.86 to 2.32$)$.

\section{Indication for caesarean section}

The most striking difference in the reported indication for caesarean section was among parous patients with higher rates of scheduled repeat caesarean section in private patients $(63.3 \%$ vs $46.7 \%, \mathrm{p}<0.000$; table 5$)$. Caesarean section on maternal request was more commonly recorded among private patients but accounted for few cases overall.

Table 1 Sociodemographic characteristics of women according to type of obstetric care

\begin{tabular}{|c|c|c|c|}
\hline $\begin{array}{l}\text { Total } \\
n=30053\end{array}$ & $\begin{array}{l}\text { Private patients } \\
\mathrm{n}=5479(\%)\end{array}$ & $\begin{array}{l}\text { Public patients } \\
\mathrm{n}=24574(\%)\end{array}$ & $\begin{array}{l}\text { OR } \\
\text { (95\% Cls) }\end{array}$ \\
\hline \multicolumn{4}{|l|}{ Maternal age (years) } \\
\hline$<20$ & $5(0.1)$ & 1063 (4.3) & $0.13(0.12 \text { to } 0.14)^{*}$ \\
\hline 20-29† & $389(7.1)$ & $10944(44.6)$ & - \\
\hline 30-39 & $4538(82.8)$ & $11843(48.1)$ & $10.80(7.83 \text { to } 13.80)^{*}$ \\
\hline$>40$ & 547 (10.0) & $724(2.9)$ & $21.30(16.46 \text { to } 26.14)^{\star}$ \\
\hline Single marital status & $386(7.0)$ & $10735(43.7)$ & $0.10(0.09 \text { to } 0.11)^{\star}$ \\
\hline Socioeconomic group Professional/manager & $3368(61.5)$ & 4904 (20.0) & $7.53(7.23 \text { to } 7.86)^{\star}$ \\
\hline Home duties† & $422(7.7)$ & $4628(18.8)$ & - \\
\hline Non-manual & $1495(27.3)$ & $9505(38.7)$ & $1.73(1.25 \text { to } 2.21)^{\star}$ \\
\hline Manual & $129(2.4)$ & $1216(4.9)$ & $1.16(1.14 \text { to } 1.18)^{*}$ \\
\hline Unemployed & $7(0.1)$ & $2898(11.8)$ & $0.03(0.01 \text { to } 0.04)^{\star}$ \\
\hline Non-classifiable & $58(1.1)$ & $1423(5.8)$ & $0.45(0.42 \text { to } 0.48)^{*}$ \\
\hline Irish nationality & 5089 (92.9) & $16243(66.1)$ & $6.69(6.02 \text { to } 7.44)^{\star}$ \\
\hline Nulliparous & 1931 (35.2) & 10439 (42.5) & $0.74(0.69 \text { to } 0.78)^{\star}$ \\
\hline Unplanned pregnancy & $452(8.2)$ & 9150 (37.2) & $0.15(0.14 \text { to } 0.17)^{\star}$ \\
\hline \multicolumn{4}{|l|}{ Gestation at booking (weeks) } \\
\hline$<12 \dagger$ & $2812(51.3)$ & 8847 (36.0) & - \\
\hline $12-20$ & $2568(46.9)$ & $13680(55.7)$ & $0.59(0.57 \text { to } 0.61)^{\star}$ \\
\hline$>20$ & $92(1.7)$ & $1872(7.6)$ & $0.16(0.15 \text { to } 0.17)^{*}$ \\
\hline Current smoker & $103(1.9)$ & 4739 (19.3) & $0.08(0.07 \text { to } 0.10)^{\star}$ \\
\hline Current alcohol use & $157(2.9)$ & $1474(6.0)$ & $0.49(0.38 \text { to } 0.82)^{\star}$ \\
\hline Illicit drug use (ever) & 67 (1.2) & $1994(8.1)$ & $0.14(0.11 \text { to } 0.18)^{*}$ \\
\hline Social worker referral & $2(0.00)$ & 961 (3.9) & $0.01(0.00 \text { to } 0.04)^{*}$ \\
\hline
\end{tabular}

${ }^{*} \mathrm{p}<0.05$.

†Reference category. 
Table 2 Medical and obstetric characteristics of women according to type of obstetric care

\begin{tabular}{|c|c|c|c|}
\hline $\begin{array}{l}\text { Total } \\
\mathrm{n}=30053\end{array}$ & $\begin{array}{l}\text { Private patients } \\
\mathrm{n}=5479(\%)\end{array}$ & $\begin{array}{l}\text { Public patients } \\
\mathrm{n}=24574(\%)\end{array}$ & $\begin{array}{l}\text { OR } \\
(95 \% \mathrm{Cl})\end{array}$ \\
\hline Medical disorders & 487 (8.9) & 2598 (10.6) & $0.83(0.75 \text { to } 0.91)^{\star}$ \\
\hline Psychiatric disorders & $542(9.9)$ & 4127 (16.8) & $0.54(0.50 \text { to } 0.60)^{*}$ \\
\hline Hepatitis C/HIV & $6(0.1)$ & 299 (1.2) & $0.09(0.04 \text { to } 0.20)^{\star}$ \\
\hline Body Mass Index $\geq 30.0$ & 565 (10.3) & 3949 (16.1) & $0.57(0.52 \text { to } 0.63)^{\star}$ \\
\hline Assisted conception & $403(7.4)$ & 335 (1.4) & $5.75(4.95 \text { to } 6.66)^{\star}$ \\
\hline Previous miscarriage & $1781(32.5)$ & 5839 (23.8) & $1.54(1.45 \text { to } 1.65)^{\star}$ \\
\hline Recurrent miscarriage & $581(10.6)$ & $1449(5.9)$ & $1.89(1.71 \text { to } 2.09)^{*}$ \\
\hline Previous termination & $254(4.6)$ & $1658(6.7)$ & $0.67(0.59 \text { to } 0.77)^{*}$ \\
\hline Previous perinatal death & $119(2.2)$ & 391 (1.6) & $1.37(1.12 \text { to } 1.69)^{*}$ \\
\hline Fetal complication & $374(6.8)$ & $1829(7.4)$ & 0.91 (0.81 to 1.02$)$ \\
\hline Maternal complication & $276(5.0)$ & $1417(5.8)$ & $0.87(0.76 \text { to } 0.99)^{\star}$ \\
\hline
\end{tabular}

\section{Perinatal outcomes}

Mean gestational age at delivery and birth weight were similar for private and public patients (table 6). Private patients were less likely to have a baby that was SGA or with a congenital abnormality. All other perinatal outcomes did not differ significantly according to type of obstetric care after adjusting for sociodemographic, medical and obstetric characteristics.

\section{DISCUSSION}

Summary of main findings

We found that private patients are more likely than public patients to have an operative vaginal delivery or a caesarean section. The greatest disparity is for scheduled caesarean sections, and twofold differences persist even after adjustment for sociodemographic, medical and obstetric factors. The difference in scheduled caesarean section rates occurred in nulliparous and parous women, and scheduled repeat caesarean section was the most common indication among parous women. Rates of emergency caesarean section are similar following spontaneous and induced labour. Perinatal outcomes are largely similar, although private patients are less likely to have a baby that is SGA or has a congenital abnormality.

\section{Strengths and limitations of the study}

The population consisted of a complete geographical cohort of women attending a busy tertiary referral maternity hospital over a 4-year period. The data were collected prospectively and ascertained routinely by a qualified midwife using a computer-guided interview. The study was limited to women with singleton pregnancies in order to evaluate obstetric practice across the full spectrum of obstetricians providing care to both public and private patients. The large size of the study population and detailed dataset allowed us to address many potential confounding factors-sociodemographic, medical and obstetric, not previously examined in such

Table 3 Mode of delivery according to type of obstetric care

\begin{tabular}{|c|c|c|c|c|}
\hline & $\begin{array}{l}\text { Private patients } \\
\mathrm{n}=5479(\%)\end{array}$ & $\begin{array}{l}\text { Public patients } \\
\mathrm{n}=24574(\%)\end{array}$ & $\begin{array}{l}\text { Crude OR } \\
(95 \% \mathrm{CI})\end{array}$ & $\begin{array}{l}\text { Adjusted OR † } \\
(95 \% \mathrm{Cl})\end{array}$ \\
\hline Spontaneous vaginal delivery & $2488(45.4)$ & $14991(61.0)$ & $0.53(0.50 \text { to } 0.56)^{*}$ & $0.55(0.52 \text { to } 0.60)^{*}$ \\
\hline Operative vaginal delivery & $1104(20.1)$ & 4048 (16.5) & $1.28(1.19 \text { to } 1.38)^{*}$ & $1.44(1.31 \text { to } 1.58)^{*}$ \\
\hline Vacuum delivery & 647 (11.8) & $2201(9.0)$ & $1.36(1.24 \text { to } 1.49)^{*}$ & $1.47(1.32 \text { to } 1.65)^{*}$ \\
\hline Forceps delivery & 457 (8.3) & $1847(7.5)$ & $1.12(1.01 \text { to } 1.25)^{*}$ & $1.21(1.06 \text { to } 1.37)^{\star}$ \\
\hline Caesarean section (all) & $1887(34.4)$ & $5535(22.5)$ & $1.81(1.70 \text { to } 1.93)^{*}$ & $1.57(1.45 \text { to } 1.70)^{\star}$ \\
\hline Scheduled caesarean section & $1150(21.0)$ & 2194 (8.9) & $2.71(2.51 \text { to } 2.93)^{*}$ & $1.99(1.80 \text { to } 2.18)^{*}$ \\
\hline Emergency caesarean section & 737 (13.5) & $3341(13.6)$ & $0.99(0.91$ to 1.08$)$ & 0.97 (0.88 to 1.08$)$ \\
\hline $\begin{array}{l}\text { Emergency caesarean section } \\
\text { Spontaneous onset labour }\end{array}$ & $233(4.3)$ & $1232(5.0)$ & $0.84(0.73 \text { to } 0.97)^{*}$ & $0.80(0.68 \text { to } 0.95)^{*}$ \\
\hline $\begin{array}{l}\text { Emergency caesarean section } \\
\text { Induction of labour }\end{array}$ & $271(4.9)$ & $1314(5.3)$ & $0.92(0.81$ to 1.05$)$ & $0.94(0.80$ to 1.10$)$ \\
\hline $\begin{array}{l}\text { Emergency caesarean section } \\
\text { No labour }\end{array}$ & $235(4.3)$ & 799 (3.3) & $1.33(1.15 \text { to } 1.55)^{\star}$ & $1.33(1.11 \text { to } 1.59)^{\star}$ \\
\hline
\end{tabular}

\section{${ }^{*} \mathrm{p}<0.05$.}

†Adjusted for maternal age, marital status, SE group, nationality, parity, smoker, medical disorders, psychiatric disorders, body mass index, assisted conception, previous perinatal death, fetal conditions, antenatal complications. 
Table 4 Mode of delivery according to type of obstetric care and parity

\begin{tabular}{|c|c|c|c|c|c|c|}
\hline & $\begin{array}{l}\text { Nulliparous } \\
\text { Private } \\
\text { patients } \\
\mathrm{n}=1931 \text { (\%) }\end{array}$ & $\begin{array}{l}\text { Public } \\
\text { patients } \\
n=10439 \\
(\%)\end{array}$ & $\begin{array}{l}\text { Crude OR }(95 \% \mathrm{Cl}) \\
\text { Adjusted OR } † \\
(95 \% \mathrm{Cl})\end{array}$ & $\begin{array}{l}\text { Parous } \\
\text { Private } \\
\text { patients } \\
\mathrm{n}=3548(\%)\end{array}$ & $\begin{array}{l}\text { Public } \\
\text { patients } \\
n=14135 \\
(\%)\end{array}$ & $\begin{array}{l}\text { Crude OR }(95 \% \mathrm{Cl}) \\
\text { Adjusted OR } † \\
(95 \% \mathrm{CI})\end{array}$ \\
\hline $\begin{array}{l}\text { Spontaneous } \\
\text { vaginal delivery }\end{array}$ & $493(25.5)$ & 4647 (44.5) & $\begin{array}{l}0.43(0.38 \text { to } 0.48)^{\star} \\
0.68(0.60 \text { to } 0.78)^{\star}\end{array}$ & 1995 (56.2) & $10344(73.2)$ & $\begin{array}{l}0.47(0.44 \text { to } 0.51)^{\star} \\
0.50(0.45 \text { to } 0.55)^{\star}\end{array}$ \\
\hline $\begin{array}{l}\text { Operative vaginal } \\
\text { delivery }\end{array}$ & 756 (39.2) & 3225 (30.9) & $\begin{array}{l}1.44(1.30 \text { to } 1.59)^{\star} \\
1.25(1.11 \text { to } 1.41)^{\star}\end{array}$ & $348(9.8)$ & $823(5.8)$ & $\begin{array}{l}1.76(1.54 \text { to } 2.01)^{*} \\
1.56(1.32 \text { to } 1.83)^{*}\end{array}$ \\
\hline Vacuum delivery & 395 (20.5) & 1669 (16.0) & $\begin{array}{l}1.35(1.20 \text { to } 1.53)^{*} \\
1.27(1.10 \text { to } 1.48)^{\star}\end{array}$ & $252(7.1)$ & $532(3.8)$ & $\begin{array}{l}1.96(1.68 \text { to } 2.28)^{*} \\
1.64(1.35 \text { to } 2.00)^{*}\end{array}$ \\
\hline Forceps delivery & $361(18.7)$ & $1556(14.9)$ & $\begin{array}{l}1.31(1.16 \text { to } 1.49)^{*} \\
1.11(0.95 \text { to } 1.29)\end{array}$ & $96(2.7)$ & $291(2.1)$ & $\begin{array}{l}1.32(1.05 \text { to } 1.67)^{\star} \\
1.32(0.99 \text { to } 1.76)\end{array}$ \\
\hline $\begin{array}{l}\text { Caesarean } \\
\text { section (all) }\end{array}$ & $682(35.3)$ & 2567 (24.6) & $\begin{array}{l}1.67(1.51 \text { to } 1.86)^{\star} \\
1.21(1.07 \text { to } 1.37)^{\star}\end{array}$ & 1205 (34.0) & 2968 (21.0) & $\begin{array}{l}1.94(1.79 \text { to } 2.10)^{*} \\
1.80(1.63 \text { to } 1.98)^{*}\end{array}$ \\
\hline $\begin{array}{l}\text { Scheduled } \\
\text { caesarean } \\
\text { section }\end{array}$ & 229 (11.9) & $475(4.6)$ & $\begin{array}{l}2.82(2.39 \text { to } 3.33)^{\star} \\
1.82(1.49 \text { to } 2.24)^{\star}\end{array}$ & $921(26.0)$ & 1719 (12.2) & $\begin{array}{l}2.53(2.31 \text { to } 2.77)^{\star} \\
2.08(1.86 \text { to } 2.32)^{\star}\end{array}$ \\
\hline $\begin{array}{l}\text { Emergency } \\
\text { caesarean } \\
\text { section }\end{array}$ & $453(23.5)$ & $2092(20.0)$ & $\begin{array}{l}1.22(1.09 \text { to } 1.37)^{*} \\
0.98(0.86 \text { to } 1.08)\end{array}$ & $284(8.0)$ & 1249 (8.8) & $\begin{array}{l}0.90(0.79 \text { to } 1.03) \\
1.04(0.88 \text { to } 1.21)\end{array}$ \\
\hline $\begin{array}{l}\text { Emergency } \\
\text { caesarean } \\
\text { section } \\
\text { Spontaneous } \\
\text { onset labour }\end{array}$ & $119(6.2)$ & $674(6.5)$ & $\begin{array}{l}0.95(0.78 \text { to } 1.16) \\
0.86(0.68 \text { to } 1.08)\end{array}$ & $114(3.2)$ & $558(3.9)$ & $\begin{array}{l}0.81(0.66 \text { to } 0.99)^{*} \\
0.92(0.72 \text { to } 1.17)\end{array}$ \\
\hline $\begin{array}{l}\text { Emergency } \\
\text { caesarean } \\
\text { section } \\
\text { Induction of } \\
\text { labour }\end{array}$ & 218 (11.3) & 1075 (10.3) & $\begin{array}{l}1.11(0.95 \text { to } 1.29) \\
0.86(0.72 \text { to } 1.03)\end{array}$ & $53(1.5)$ & $239(1.7)$ & $\begin{array}{l}0.88(0.65 \text { to } 1.19) \\
0.99(0.69 \text { to } 1.41)\end{array}$ \\
\hline $\begin{array}{l}\text { Emergency } \\
\text { caesarean } \\
\text { section } \\
\text { No labour }\end{array}$ & $116(6.0)$ & 343 (3.3) & $\begin{array}{l}1.88(1.52 \text { to } 2.34)^{*} \\
1.63(1.25 \text { to } 2.13)^{\star}\end{array}$ & 119 (3.4) & 456 (3.2) & $\begin{array}{l}1.04(0.85 \text { to } 1.28) \\
1.21(0.95 \text { to } 1.55)\end{array}$ \\
\hline
\end{tabular}

detail-and to evaluate associations with greater precision.

Data on smoking, alcohol intake, previous illicit drug use and termination of pregnancy relied on selfreporting and it is possible that there may have been under-reporting. Each neonate was examined at delivery and again prior to hospital discharge. Longer term follow-up would be required to detect all cases of congenital anomalies and neurodevelopmental deficit. A standard system for classifying caesarean sections, such

Table 5 Indication for caesarean section according to parity

\begin{tabular}{|c|c|c|c|c|c|c|}
\hline & $\begin{array}{l}\text { Nulliparous } \\
\text { Private patients } \\
\mathrm{n}=682(\%)\end{array}$ & $\begin{array}{l}\text { Public patients } \\
\mathrm{n}=2567(\%)\end{array}$ & p Value & $\begin{array}{l}\text { Parous } \\
\text { Private patients } \\
\mathrm{n}=1205(\%)\end{array}$ & $\begin{array}{l}\text { Public patients } \\
\mathrm{n}=2968(\%)\end{array}$ & p Value \\
\hline Scheduled repeat caesarean & - & - & & 763 (63.3) & $1385(46.7)$ & $<0.000$ \\
\hline Maternal condition & $96(14.1)$ & $164(6.4)$ & $<0.000$ & $102(8.5)$ & $233(7.9)$ & 0.51 \\
\hline Fetal condition & $75(11.0)$ & $206(8.0)$ & 0.01 & $43(3.6)$ & $187(6.3)$ & $<0.000$ \\
\hline Malpresentation & 99 (14.5) & $328(12.8)$ & 0.23 & 59 (4.9) & $219(7.4)$ & 0.004 \\
\hline Placental condition & $16(2.3)$ & $31(1.2)$ & 0.03 & $46(3.8)$ & $107(3.6)$ & 0.74 \\
\hline Maternal request & $29(4.3)$ & $22(0.2)$ & $<0.000$ & $6(0.5)$ & $13(0.4)$ & 0.79 \\
\hline Poor obstetric history & $4(0.6)$ & $0(0.0)$ & 0.002 & $12(1.0)$ & $13(0.4)$ & 0.03 \\
\hline Labour complication & 337 (49.4) & $1759(68.5)$ & $<0.000$ & $169(14.0)$ & $801(27.0)$ & $<0.000$ \\
\hline Failed induction of labour & $26(3.8)$ & $57(0.5)$ & 0.02 & $5(0.4)$ & $10(0.3)$ & 0.78 \\
\hline
\end{tabular}


Table 6 Perinatal outcomes according to type of obstetric care

\begin{tabular}{|c|c|c|c|c|}
\hline & $\begin{array}{l}\text { Private patients } \\
\mathrm{n}=5479(\%)\end{array}$ & $\begin{array}{l}\text { Public patients } \\
\mathrm{n}=24574(\%)\end{array}$ & OR $(95 \% \mathrm{Cl})$ & Adjusted OR† $(95 \% \mathrm{Cl})$ \\
\hline Gestational age (weeks), mean (SD) & $39.4(1.8)$ & $39.6(2.0)$ & - & - \\
\hline Birth weight (grams), mean (SD) & $3498(550)$ & $3428(595)$ & - & - \\
\hline Preterm birth <37 weeks (\%) & $268(4.9)$ & $1448(5.9)$ & $0.82(0.72 \text { to } 0.94)^{*}$ & $0.96(0.85$ to 1.17$)$ \\
\hline Very preterm birth <32 weeks (\%) & $53(1.0)$ & $322(1.3)$ & $0.74(0.55 \text { to } 0.99)^{*}$ & $0.82(0.59$ to 1.16$)$ \\
\hline Birth weight $<10$ th centile (\%) & $446(8.1)$ & 3298 (13.4) & $0.57(0.52 \text { to } 0.63)^{*}$ & $0.74(0.65 \text { to } 0.83)^{*}$ \\
\hline Male infant $(\%)$ & $2871(52.4)$ & $12612(51.3)$ & $1.04(0.99$ to 1.11$)$ & 1.05 (0.98 to 1.13$)$ \\
\hline Apgar score $<7$ at $5 \min (\%)$ & $37(0.7)$ & $209(0.9)$ & $0.81(0.57$ to 1.15$)$ & $0.76(0.51$ to 1.14$)$ \\
\hline Admitted to neonatal unit (\%) & $723(13.2)$ & $3549(14.5)$ & $0.90(0.83 \text { to } 0.98)^{*}$ & $0.94(0.85$ to 1.04$)$ \\
\hline Congenital abnormality (\%) & $29(0.5)$ & $189(0.8)$ & 0.69 (0.46 to 1.02$)$ & $0.51(0.33 \text { to } 0.80)^{*}$ \\
\hline Aneuploidy (Trisomy/XO) (\%) & $11(0.2)$ & $42(0.2)$ & 1.18 (0.61 to 2.28$)$ & $0.62(0.28$ to 1.35$)$ \\
\hline Perinatal death (\%) & $24(0.4)$ & $155(0.6)$ & $0.69(0.45$ to 1.07$)$ & 0.79 (0.47 to 1.32$)$ \\
\hline
\end{tabular}

as the Robson classification, ${ }^{23}$ allows direct comparisons between centres; however, for this study we felt it was more informative to use the caesarean section indication recorded by the operator, which provided additional detail within categories. Inevitably, it was not possible to ascertain whether the decision for an operative delivery was driven by the obstetrician, or the woman, or both, except in the small number of cases designated 'maternal request'. While the number of official complaints was low, it was not possible to assess patient satisfaction with the care received. Lastly, as with any cohort study, there may be residual confounding that we were unable to control for.

\section{Comparison with the existing literature}

As with previous reports, this study shows that private patients are at increased risk for operative deliveries. $^{16}$ 20-22 24-26 Compared with previous studies, we were able to examine the impact of sociodemographic, medical and obstetric characteristics on mode of delivery. We found that the differences observed in relation to operative deliveries were not explained by higher rates of medical or obstetrical complications among private patients, although like other studies some of the disparity could be attributed to differences in maternal age and socioeconomic status. ${ }^{6}{ }^{12}{ }^{20-22} 24-26$ If anything, private patients had less maternal and fetal complications but a higher rate of caesarean sections for those indications. Unlike other studies, our cohort evaluated public and private obstetric care in an integrated clinical setting with the same midwifery and operating theatre staff, and with hospital-wide protocols. In addition to mode of delivery, we evaluated perinatal outcomes.

The largest magnitudes of difference between public and private patients in terms of mode of delivery were scheduled caesarean sections in nulliparous women and scheduled repeat caesarean sections in parous women. Undoubtedly older maternal age, higher socioeconomic status and subfertility among private patients accounted for some of the increase in nulliparous scheduled caesarean sections. It may be that older, better educated women are more strongly influenced by the choices obstetricians would make for themselves, or that their own preferences more closely mirror these views. There are several studies reporting strong personal preferences among some obstetricians for scheduled caesarean section, and indeed many of the private patients were health professionals. ${ }^{27-30}$ Another common argument in favour of primary scheduled caesarean section is that it avoids damage to the pelvic floor. ${ }^{27} 29$ This was unlikely to have been a dominant factor in this cohort given the higher rate of operative vaginal deliveries (both vacuum and forceps) among private patients. Previous studies from Chile and Italy reported that obstetricians had a powerful influence on the decision for caesarean section, perhaps driven by scheduling pressures, and that this frequently contravened the woman's preference for a natural delivery. ${ }^{24} 31$ Elective decision-making within a UK or Irish setting is more likely to be shared, but the influence of an obstetrician's stated or subliminal perspective should not be underestimated.

The scheduled caesarean section rate among parous private patients was twice that of public patients, and in two-thirds of cases the indication was scheduled repeat caesarean section. This indicates a strong preference among obstetricians and their private patients to avoid labour after a previous caesarean section. Ironically, all public patients with a previous caesarean section are counselled by the same group of obstetricians and yet the delivery outcomes are very different. It may be that women who want a repeat caesarean section think they are more likely to get it under private care, or it may be that the higher rate of scheduled caesareans in the nulliparous private patients results in an escalation in repeat caesarean sections with subsequent births. A systematic review of the literature reports inconsistent evidence that having private health insurance is a barrier to the uptake and success of VBAC. $^{32}$ How risk-based 
information is provided is likely to be the critical factor. ${ }^{30}$ A randomised controlled trial of two decision-aids for women with a previous caesarean section reported reduced decisional conflict and an increase in successful VBAC among the group of women randomised to computerised decision analysis compared with routine care. ${ }^{33}$

\section{Clinical service implications}

Many would argue that co-location of public and private patient care works well. Private patients select their preferred consultant, receive continuity of care and feel secure in the knowledge that the full range of emergency services within the public system is available if needed. Public patients benefit from the additional resource that enters the health system. Nonetheless, this study has highlighted important differences in operative delivery rates that raise questions about equity. One would expect that every woman, irrespective of the funding source, is managed in a way that results in the best possible outcomes for mother and baby. It was reassuring that perinatal outcomes were equally good for the public and private patients within this cohort. Although speculative, it seems quite likely that private patients are provided with greater choice in relation to a scheduled caesarean section. It is debatable whether this is actually in the woman's best interest, particularly when it comes to the next birth. ${ }^{1632}{ }^{34}$ What does need to be addressed is whether higher rates of scheduled caesarean sections among private patients create access issues for medically indicated caesarean sections, and whether these patients place a disproportionate burden on the service in the postoperative period. ${ }^{35}$

\section{CONCLUSIONS}

Privately funded obstetric care is associated with higher rates of operative deliveries that are not fully accounted for by medical or obstetric risk differences. Adverse perinatal outcomes are neither increased nor decreased in private patients despite higher rates of intervention. Healthcare systems that include public and private patients need to reflect on the potential for disparate rates of intervention and the implications in terms of equity, resource use and income generation. Future research needs to explore the drivers behind decisions to perform caesarean sections, and whether the high rate of caesarean sections among private patients has long-term consequences.

Acknowledgements The authors would like to thank the midwives who took great care with history-taking and data entry and the IT department for assistance with data extraction. We would like to acknowledge B Cleary who provided assistance with the database.

Contributors DJM (guarantor) and TF had the original idea for the study. DJM was responsible for data cleaning and recoding and performing the analyses. Both authors drafted and revised the manuscript.

Funding This research received no specific grant from any funding agency in the public, commercial or not-for-profit sectors.
Competing interests DJM worked as an obstetrician within the NHS for 14 years and over the past 7 years has provided both public and private obstetric care to women in Ireland.

Ethics approval Study No: 22-2009; updated 09-2011.

Provenance and peer review Not commissioned; externally peer reviewed.

Data sharing statement No additional data are available.

Open Access This is an Open Access article distributed in accordance with the Creative Commons Attribution Non Commercial (CC BY-NC 3.0) license, which permits others to distribute, remix, adapt, build upon this work noncommercially, and license their derivative works on different terms, provided the original work is properly cited and the use is non-commercial. See: http:// creativecommons.org/licenses/by-nc/3.0/

\section{REFERENCES}

1. Wilkinson C, Brennan D. Universal healthcare-trick or treat?. http:// www.irishhealth.com (last accessed 7 Aug 2013).

2. Freeman M. Expert group to examine universal health insurance proposal. http://www.thejournal.ie (17 Feb 2012). (accessed 7 Aug 2013).

3. Public and private patients in Public hospitals. Guidance to health service management on the treatment of public and private patients. http://www.hse.ie (16 Sep 2009) (accessed 7 Aug 2013).

4. Kmietowicz Z. Hospitals will be able to earn $49 \%$ of their income from private patients from October. BMJ 2012;345:e4823.

5. Fineberg HV. Shattuck lecture. A successful and sustainable system -how to get there from here. N Engl J Med 2012;366:1020-7.

6. O' Leary CM, De Klerk N, Keogh J, et al. Trends in mode of delivery during 1984-2003: can they be explained by pregnancy and delivery complications? Br J Obstet Gynaecol 2007;114:855-64.

7. National Collaborating Centre for Women's and Children's health. Caesarean section: clinical guidelines. London: Royal College of Obstetricians and Gynaecology, 2004.

8. Belizan JM, Althabe F, Barros FC, et al. Rates and implications of caesarean sections in Latin America: ecological study. BMJ 1999;319:1397-400.

9. Kirby RS. Trends in labor induction in the United States: is it true that what goes up must come down? Birth 2004;31:148-51.

10. Leitch CR, Walker JJ. The rise in caesarean section rate: the same indications but a lower threshold. Br J Obstet Gynaecol 1998;105:621-6.

11. Cleary-Goldman J, Malone FD, Vidaver J, et al. Impact of maternal age on obstetric outcome. Obstet Gynecol 2005;105:983-90.

12. Bell JS, Campbell DM, Graham WJ, et al. Do obstetric complications explain high caesarean section rates among women over 30 ? A retrospective analysis. BMJ 2001;322:894-5.

13. Vaughan D, Cleary B, Murphy DJ. Delivery outcomes for nulliparous women at the extremes of maternal age-a cohort study. $\mathrm{Br} \mathrm{J} \mathrm{Obstet}$ Gynaecol 2013; [Epub ahead of print 21 Jun 2013]. doi:10.1111/ 1471-0528. 12311

14. BirthChoiceUK [Internet]. United Kingdom; 2010. http://www. birthchoiceuk.com/Professionals/Frame.htm (accessed 15 Feb 2013).

15. Consumer guide to maternity services in Ireland [Internet]. Ireland; 2010. http://www.bump2babe.ie/column/N/statistics/ (accessed 15 Feb 2013).

16. Soltani H, Sandall J. Organisation of maternity care and choices of mode of birth: a worldwide view. Midwifery 2012;28:146-9.

17. Turner M. Should women be able to request a caesarean section? Yes. BMJ 2011;343:d7570.

18. Rouhe $\mathrm{H}$. Should women be able to request a caesarean section? No. BMJ 2011;343:d7565.

19. Villar J, Carroli G, Zavaleta N, et al. World Health Organization 2005 Global Survey on Maternal and Perinatal Health Research Group. Maternal and neonatal individual risks and benefits associated with caesarean delivery: multicentre prospective study. BMJ 2007;335:1025

20. Movsas TZ, Wells E, Mongoven A, et al. Does medical insurance type (private vs public) influence physician's decision to perform Caesarean delivery? J Med Ethics 2012;38:470-3.

21. Lipkind HS, Duzyi C, Rosenberg TJ, et al. Disparities in cesarean delivery rates and associated adverse neonatal outcomes in New York City hospitals. Obstet Gynecol 2009;113:1239-47.

22. Einarsdottir K, Stock S, Haggar F, et al. Neonatal complications in public and private patients: a retrospective cohort study. BMJ Open 2013;3:pii:e002786.

23. Robson M. Classification of cesarean sections. Fetal Matern Med Rev 2001;12:23-9. 
24. Barbadoro P, Chiatti C, D'Errico MM, et al. Caesarean delivery in south Italy: women without choice. A cross sectional survey. PLoS ONE 2012;7:e43906.

25. Coulm B, Le Ray C, Lelong N, et al. Obstetric interventions for low-risk pregnant women in France: do maternity unit characteristics make a difference? Birth 2012;39:183-91.

26. Rebelo F, da Rocha CM, Cortes TR, et al. High cesarean prevalence in a national population-based study in Brazil: the role of private practice. Acta Obstet Gynecol Scand 2010;89: 903-8.

27. Al-Mufti R, McCarthy A, Fisk NM. Survey of obstetricians' personal preference and discretionary practice. Eur J Obstet Gynecol Reprod Biol 1997;73:1-4

28. Wright JB, Wright AL, Simpson NA, et al. A survey of trainee obstetricians preferences for childbirth. Eur J Obstet Gynecol Reprod Biol 2001;97:23-5.

29. Land R, Parry E, Rane A, et al. Personal preferences of obstetricians towards childbirth. Aust N Z J Obstet Gynecol 2001;41:249-52.
30. Sur S, Murphy KW, Mackenzie IZ Delivery after caesarean section: consultant obstetricians' professional advice and personal preferences. J Obstet Gynaecol 2009;29:212-16.

31. Murray SF. Relation between private health insurance and high rates of caesarean section in Chile: qualitative and quantitative study. $B M$ 2000;321:1501-5.

32. Catling-Paull C, Johnston R, Ryan C, et al. Non-clinical interventions that increase the uptake and success of vaginal birth after caesarean section: a systematic review. J Adv Nurs 2011;67:1662-76

33. Montgomery AA, Emmett CL, Fahey TP, et al. DiAMOND Study Group. Two decision aids for mode of delivery among women with previous caesarean section: randomised controlled trial. BMJ 2007;334:1305.

34. Bahl R, Strachan B, Murphy DJ. Outcome of subsequent pregnancy three years after previous operative delivery in the second stage of labour: cohort study. BMJ 2004;328:311.

35. Einarsdottir K, Kemp A, Haggar FA, et al. Increase in caesarean deliveies after the Australian Private Health insurance incentive policy reforms. PLOS ONE 2012;7:e41436. 